\title{
Pietas y guerra civil
}

\author{
Federico Santangelo \\ Newcastle University, Reino Unido \\ federico.santangelo@ncl.ac.uk
}

\begin{abstract}
Resumen:
Las guerras civiles del período tardorrepublicano son un período de profunda agitación política, en el que la cohesión y la viabilidad de la comunidad cívica son severamente cuestionadas. Esto posee significativas ramificaciones religiosas, dado que la relación entre la comunidad y los dioses es desafíada y en ocasiones socavada. No obstante, las afirmaciones relativas a la piedad -el escrúpulo y la observancia religiosa, así como una conexión duradera con los dioses- juegan un papel central en los discursos contemporáneos sobre la guerra civil y sin duda en el funcionamiento de los conflictos militares mismos. Este trabajo traza estas afirmaciones buscando recuperar la centralidad de las preocupaciones religiosas de los sectores en guerra y explorar sus implicaciones políticas e intelectuales.
\end{abstract}

Palabras ClaVE: Pietas, Religión, Italia romana, Ciudades, Fundación.

\section{Aвstract:}

The civil wars of the late Republican period are a period of deep political turmoil, in which the cohesion and viability of the civic community are harshly put into question. That has significant religious ramifications, as the relationship between the community and the gods is challenged and at times undermined. Yet claims to piety - to religious scruple and observance, as well as to an enduring connection with the gods - play a major role in contemporary discourses on civil war, and indeed in the running of the military conflicts themselves. This paper charts them by seeking to restore centrality to the religious concerns of the warring parties and explore their political and intellectual implications.

KEYWORDS: Pietas, Religion, Roman Italy, Cities, Foundation.

\section{Pietas en disputa}

Está fuera de discusión que la noción de pietas debe incluirse en cualquier debate acerca de las guerras civiles de la última República. El hecho mismo de que reciba un lugar de privilegio en el clipeus virtutis de Augusto debería ser decisivo en sí mismo ${ }^{1}$; incluso aquellos con un conocimiento superficial de la Eneida reconocen la relevancia política de la descripción del pius Aeneas. Si nos remontamos a la época del triunvirato, el papel que pietas desempeña en el discurso político de Sexto Pompeyo o la decisión de Lucio Antonio, figura clave en la guerra de Perusia, de añadir la palabra pietas a su propio nombre -un considerable avance respecto de lo que Sila había hecho con felicitas cuatro décadas antes- son poderosos recordatorios del peso y significación del concepto en todos los sectores del espectro político. Existirán, no obstante, distintas visiones en torno a cuán seriamente debe tomarse la noción de pietas en el contexto de las luchas internas y de la guerra a escala del Mediterráneo. Hasta cierto punto, las reservas modernas respecto del poder explicativo del poder de pietas pertenecen a un contexto intelectual e histórico más amplio, en el que se han atribuido significados marcadamente diferentes al lugar de la religión en la Roma republicana: para expresarlo con un resumen en cierto modo superficial de una idea equivocada que sigue estando bastante extendida, si la religión en Roma es siempre una cuestión política, sujeta a las presiones de la controversia y la manipulación partidarias, entonces la piedad romana también es una cuestión política, y uno debería abstenerse de buscar instancias de piedad genuina más allá del cumplimiento de los requisitos de la ortopraxia ritual, o del despliegue de poderosas y generalizadas fórmulas políticas.

Recepción: 22 de enero de 2019 | Aprobación: 20 de febrero de 2019 | Publicación: 05 de septiembre de 2019 
Mucho se ha hecho en los últimos quince años para devolver pietas a su legítimo lugar en el discurso político y cultural de la República tardía. Matthew Roller ha escrito páginas esclarecedoras acerca de su importancia como una "community-oriented... ethical category", que justifica su consideración detallada junto con virtus, y se presta a una lectura tanto a través de su empleo "en acciones" como su uso "en actitudes": a través de actos de pietas y a través de un compromiso personal para con pietas ${ }^{2}$. En un período de guerra civil, ambas categorías son colocadas bajo una presión apenas sostenible: las guerras civiles son conflictos en los cuales están en juego "discursos éticos rivales", los mismos vínculos del cuerpo cívico son tema de controversia y la competencia por las nociones orientadas hacia la comunidad se hace más intensa. La lectura de textos familiares ha generado asimismo interpretaciones valiosas. Anton Powell ha discrepado con aquellos que consideran la pietas de Eneas como una cualidad atemorizadora, o incluso opaca, y ha propuesto la necesidad de una apreciación minuciosa de la función de pietas en el poema como un todo ${ }^{3}$. Al hacerlo, ha hablado provocativamente de un "robo de la pietas" por parte de Octaviano y su facción, por apropiarse de las reivindicaciones de dicha cualidad que habían realizado Antonio y Sexto Pompeyo y, en este último caso, con mucha mayor credibilidad que la que podían tener los miembros del triunvirato. Sin duda, continúa Powell, las proscripciones eran el gran problema histórico y moral que debía confrontar la generación de Virgilio, y un problema en el que la pietas para con los familiares y amigos (el sentido primario de la palabra, según Powell) jugaba un papel crucial. Virgilio "el partisano" se propone tornar la pietas contra aquellos que se oponían a Octaviano, y la convierte en "his title to rule" ${ }^{4}$. La invitación a colocar pietas en el núcleo mismo de la política del triunvirato ha sido estudiada por Kathryn Welch, quien ha encuadrado todo su relato sobre Sexto Pompeyo en torno a la impotancia de pietas para su discurso público, sobre todo en su acuñación, y ha argumentado que las acciones de Pompeyo podían convincentemente ser consideradas "piadosas" por muchos de sus contemporáneos, en particular en comparación con la conducta del triunvirato: la idea de Pompeyo como el líder de un "estado pirata" ha sido desterrada definitivamente 5 . El discurso ideológico que sostuvo su operación política era tan ambicioso como elaborado.

La idea de que pietas juega un papel central en los acontecimientos del período del triunvirato, no obstante, había sido un punto largamente identificado, aun cuando muchos han tendido a darlo por sentado. En The Roman Revolution, Syme lo estableció firmemente como la fuerza ideológica impulsora de las guerras civiles que llevaron a la caída de la República. El problema se establece en términos con cierto dejo positivista, que recuerdan a Fustel de Coulanges o a Glotz: "The family was older than the State; and the family was the kernel of a Roman political faction. Loyalty to the ties of kinship in politics was a supreme obligation, often imposing inexpiable vendettas. Hence the role of the words 'pius' and 'pietas' in the revolutionary wars"6. En lo que sigue inmediatamente, Syme traza las reivindicaciones en pugna realizadas entre los idus de marzo y Accio, subrayando cómo la pietas para con César resultó central para el ascenso de Octaviano. Fue el impulso de pietas lo que le permitió invalidar el acuerdo que Antonio había logrado con los asesinos de César y lo que le dio, junto con un "estado de emergencia pública", la "excusa para la sedición". La importancia de pietas es resaltada con mayor contundencia al final del capítulo sobre las proscripciones, cuando se bosqueja la caída (o, en efecto, como lo plantea Syme, la abolición) de la República, y se toma el comentario de Tácito sobre los veinte años de continua discordia luego del tercer consulado de Pompeyo (Ann. III.28.2: non mos, non ius) para proveer un relato condensado del período. No obstante, apunta Syme, pietas para con César es el punto por el cual los cesarianos justifican sus acciones: "Pietas prevailed, and out of the blood of Caesar the monarchy was born" (201) ${ }^{7}$. Aun cuando pietas permanezca firmemente en el conjunto de "clichés políticos" de la "era revolucionaria", es una noción que puede aportar un conocimiento significativo de los procesos históricos de esa época. Para parafrasear a otro gran maestro de la prosa inglesa, es muy posible que pietas estuviera contaminando todo: por esa misma razón, merece un escrutinio minucioso. 


\section{LOS PILARES DE PIETAS}

Puede afirmarse, de hecho, que el peso de pietas se comprende mejor como parte de un problema más amplio, estrechamente vinculado: su lugar en una época de guerra civil. Las Wortstudien son necesarias y, con frecuencia, provechosas ${ }^{8}$; en este caso, no obstante, son fuertes los argumentos a favor de buscar más allá de los testimonios de un término como pietas, sin importar cuán frecuentes e infaliblemente cargados de implicaciones puedan ser, y de volverse hacia la cuestión más amplia de cómo en una era de conmoción y disrupción sin igual se abordaba el adecuado compromiso para con la familia, los conciudadanos y los dioses. Si uno se prepara para observar más allá de las apariciones atestiguadas del término pietas, puede lograrse una comprensión más sólida de su alcance y una mejor apreciación de su significación profunda y de su valor. Un notable incidente de una guerra civil romana posterior, la del $69 \mathrm{~d}$. C., provee un relato especialmente claro de las cuestiones en juego, incluso en el período tardorrepublicano.

Poco después de la victoria de sus tropas en Bedriaco, probablemente hacia fines de mayo, Vitelio visita la ciudad vecina de Cremona, que había servido como cuartel general de su lugarteniete Aulo Cecina en los meses previos (Hist. II.70). Es recibido con una sesión especial de juegos gladiatorios en un anfiteatro de madera rápidamente levantado, y luego expresa el deseo de visitar el campo de batalla: cuarenta días después del enfrentamiento, a fines de mayo del 69, la escena era horriblemente repugnante, con pilas de cadáveres y una campiña devastada ${ }^{9}$. El pueblo de Cremona había decorado de manera peculiar el camino que llevaba al lugar de la batalla con guirnaldas y rosas, y había erigido altares construidos especialmente, sobre los que realizaban sacrificios en honor a Vitelio (según señala Tácito con dureza, regium in morem, "como se haría para un rey"). Irónicamente subraya que pronto sufrirían un destino horrible a manos de las tropas de Vespasiano, que capturó y destruyó la ciudad pocos meses más tarde. El foco se traslada luego a Vitelio y su séquito: algunos le describían al general -que todavía estaba viajando a Italia el día del combatecómo se habían desarrollado las operaciones, otros alardeaban sobre sus logros; algunos se deleitaban en la contemplación de los muertos, algunos derramaban lágrimas por la muerte de sus conciudadanos y reflexionaban acerca de lo ocurrido. Más provocativamente, sin embargo, fue Vitelio quien no estuvo a la altura de las circunstancias: no exhibió ningún dolor ante la vista de miles de conciudadanos que no habían recibido el entierro correspondiente (tot milia insepultorum ciuium). De hecho, estaba satsifecho (laetus) con lo que veía, y decidió realizar un sacrificio en ese lugar: al igual que el pueblo de Cremona, desconocía el hado que le estaba reservado. Como ha notado G. Chilver, los juegos de gladiadores en Cremona pueden haber sido parte de un festival religioso, posiblemente vinculado al culto de los muertos ("an act of piety rather than of sadism" ${ }^{10}$. Esto resulta significativo, pero irrelevante a los fines de la presente discusión: lo que importa es que se pudiera construir una lectura tan hostil de la conducta de Vitelio y de sus implicaciones rituales.

Este pasaje -que no incluye una sola mención de la palabra pietas, pero que está fuertemente vinculado a cuestiones relativas a la piedad-suscita algunos temas de gran importancia para nuestros propósitos: el énfasis en los problemas planteados por la muerte de los conciudadanos en la guerra, la obligación del vencedor de exhibir mesura y, sin duda, el lugar que posee la compasión en esa conexión; el cometido que cumplen los rituales religiosos y su correcta realización en el contexto de una división cívica irreparable; el tratamiento de los cadáveres; el rol de las comunidades locales en el marco de una guerra civil que tiene una relevancia de mucho mayor alcance.

La pregunta acerca de cómo afrontar la muerte de los conciudadanos en un conflicto civil y, de modo más general, el problema de la discordia civil, ha recibido con justicia una minuciosa atención en algunos estudios de los últimos años sobre el desarrollo del triunfo romano a fines de la república. Carsten Lange ha demostrado recientemente el grado de ingenuidad y de disciplina que se ha puesto en reconsiderar la tradición establecida de la concesión de triunfos para adecuarse a un contexto en el que se estaba librando una cantidad de guerras civiles y en el que los límites entre lo propio y lo extranjero eran con frecuencia imprecisos ${ }^{11}$. El 
principio de que los triunfos podían otorgarse solamente al finalizar una guerra contra un enemigo exterior se mantenía, y la presencia de enemigos extranjeros debía constatarse para garantizar un triunfo al final de una guerra civil: la campaña de Accio es, por supuesto, un ejemplo clásico. Las repercusiones de Mutina, por el contrario, presentaron problemas sin precedentes: a diferencia de la campaña de Munda, la guerra se había librado en suelo itálico, y la controversia que la había desencadenado estaba inextricablemente ligada a las operciones del gobierno romano y el proceso político disfuncional desarrollado después de los idus de marzo.

Un problema de tal magnitud requería una solución que estuviera firmemente impregnada de argumentos legales y religiosos sensatos, y podemos entrever la complejidad del tema en cuestión a partir de un pasaje de Cicerón cuya importancia ha sido correctamente enfatizada por Lange $(88,113)$. En la Filípica XIV, pronunciada el 21 de abril del 43, Cicerón señala que su evaluación duradera de Antonio como enemigo público (hostis) ha sido ahora justificada por los eventos recientes, y procede a discutir una propuesta presentada en esa sesión por el cónsul P. Servilio Isaurico (cos. 48) para decretar supplicationes que marcaran la victoria de los cónsules Pansa e Hirtio y de Octaviano, y en reacción a los mensajes (ex litteris) enviados a Roma por los magistrados victoriosos (XIV.22-24). Es un asunto de ius divinum -de piedad-con implicancias políticas de peso. Cicerón propone una breve arqueología de las instancias similares en las que no se pidió ni otorgó una supplicatio, empezando por la victoria de Sila en el 82 y terminando con Farsalia. César, sin embargo, sí recibió supplicationes después de Alejandría y Zela; la relación entre victorias extranjeras y triunfo, después de todo, estaba largamente establecida. Cicerón también pasa por alto Tapso y Munda, y la omisión probablemente no es ingenua ${ }^{12}$. Su postura más general, no obstante, se establece con claridad: Antonio debería ser tratado a la par de los enemigos extranjeros, ya que su victoria podría haber presentado una amenaza existencial para Roma; al otorgar las supplicationes, el Senado al mismo tiempo marcará a Antonio como enemigo público ${ }^{13}$. Al planear un acto de agradecimiento público a los dioses por el apoyo que brindaron a la ciudad, el Senado también está organizando un acto que redefine los términos de la guerra civil. No hay una división significativa entre la toma de decisiones políticas y la evaluación técnica de un experto acerca de qué acción ritual es necesaria. El ejercicio de la piedad permite que uno defina los términos del problema al que se enfrenta y vislumbrar una solución a largo plazo. Es adecuado saludar a los vencedores de Mutina como imperatores, en particular porque piden recibir esta distinción: al hacerlo, puede obtenerse la orientación apropiada de las acciones. La piedad, en esta instancia, también ofrece una ocasión formidable para la negación. Brinda la oportunidad de sugerir que no se está desarrollando ninguna guerra civil; que, sea cual sea el conflicto que tiene lugar, es contra el extranjero.

Por supuesto, podría sugerirse que la sofisticación que Cicerón exhibe al discutir las circunstancias que respaldan el otorgamiento de supplicationes es una jugada política y retórica que no debería ser considerada la regla o el síntoma de tendencias más amplias en la cultura política romana. Sin duda, siempre hay lugar para argumentar cierto tipo de excepcionalidad ciceroniana, pero existen otras instancias en este período en las que las consideraciones de derecho público, y obviamente de ius divinum, producen un impacto demostrable en las decisiones políticas que se toman y en los modos en que se configura el discurso político. Casio Dión (XLI.43) realiza una pausa para reflexionar sobre la importancia de la opción de los pompeyanos, que no eligieron nuevos magistrados para el año 48 a. C. luego del cruce a Grecia, debido a que no se había aprobado ninguna lex curiata autorizando su elección: ese tipo de legislación sólo podía ser aprobada en Roma ${ }^{14}$. Casio Dión explica la reticencia a ir contra la práctica tradicional como surgida de un escrúpulo por no violar requisitos formales bien establecidos; admite que se alzaron en armas contra su patria y señala que podrían haber tenido motivos para nombrar nuevos magistrados en virtud de que los dos cónsules del 49 a. C., así como centenares de senadores, estaban allí presentes; incluso se había identificado una delegación de sacerdotes para llevar adelante algunos rituales augurales. Tanto su fuerza política como la determinación que habían demostrado al tomar una postura en contra de César hacen que su decisión de no hacer alarde del requisito de una lex curiata aparezca más extraordinaria aún. La voluntad de acatar las limitaciones impuestas por la pietas es una consideración que deben tener presente aquellos que son conscientes de lo que les espera 
después de terminada la guerra. No se pueden eliminar los precedentes a la ligera, incluso en un contexto en el cual, como subraya Casio Dión hacia el final de su discusión del episodio, dos hombres sobresalen como las fuerzas más influyentes de su tiempo, independientemente de su estatus legal (XLI.43.5).

La piedad es especialmente significativa en un momento en el que parecen perderse las coordenadas básicas de la coexistencia cívica, y en el que parece existir un fuerte peligro de perder de vista todo tipo de límites y restricciones. Cuando reflexiona sobre las consecuencias de la marcha de Sila sobre Roma en el 88 y su importancia para la periodización, Apiano puntualiza que después del 88 todas las sediciones fueron resueltas sólo mediante el poder de las armas y que a partir de la marcha de Sila sobre Roma ya no existió ninguna "restricción respecto de la violencia ni a partir del sentido del remordimiento, o del respeto por la ley, las instituciones o la patria" (BCiv. I.60): los filtros morales y políticos dejaron de aplicarse y el precedente establecido por Sila llevó a otros a elegir pasos igualmente divisorios y abrasivos. La elección de deshacerse de todo tipo de limitación es, ante todo, política: es la decisión de abolir la política. Este nuevo modo de pensar, no obstante, conlleva asimismo algunas consecuencias indeseadas e imprevistas. La guerra civil descontrolada enceguece a los hombres y los lleva a realizar acciones que están más allá de todo arreglo y más allá de toda expiación. Un fragmento de Sisena recoge una historia que nos lleva al centro mismo de las luchas internas: durante lo que se denominó bellum Octavianum, en el 87 a. C., un soldado de Cn. Pompeyo Estrabón mata a su hermano, que pelea para el otro bando. Cuando se da cuenta de lo que ha hecho, se quita la vida: no se puede pensar en la supervivencia después de la muerte de un familiar cercano, la cual ha derivado en la desaparición de la unidad de la familia (pietas, se podría decir en los términos de Syme, en su nivel más básico, que precede y presupone el nivel de la comunidad política). Al darse cuenta de que la familia ha llegado a su fin, la vida ya no vale la pena ser vivida, independientemente de cuán profundas puedan ser las lealtadas políticas individuales. Livio también relata esta historia, y las Periochae añaden un detalle que dan a la escena un ambiente sacrificial perturbador: el sobreviviente construye una pira funeraria para su hermano y él mismo se quema con el fuego con el que se crema el cadáver de aquel (LXXIX.2). Se conoce un resumen de la versión de Sisena a partir de Tácito, quien contrasta el episodio del 87 con la conducta de un soldado común que había peleado para el lado flavio y había matado a su hermano en batalla: les pidió a sus comandantes que le dieran una recompensa ${ }^{15}$. Tácito distingue su proceder como una instancia de la degradación de la moral en el año de los cuatro emperadores. De manera reveladora, esa pérdida de toda moral rectora se agrava por la falta de habilidades para la toma de decisiones: los líderes flavios no se prestan a recompensar ese acto tan despreciable, pero tampoco se sienten en la posición de castigarlo sobre la base de la prudencia militar. Presentan un pretexto dilatorio y el resultado del asunto queda sin ser registrado.

La cuestión de la moderación -elegir no atacar o no herir a ciertos enemigos, en ciertas circunstanciasestá inextricablemente unida al problema de las fronteras de la comunidad política al finalizar la guerra: revela una preocupación por la posibilidad y las dificultades de la reconciliación. A propósito de esto, se presenta un caso paradójico a propósito de las proscripciones, en especial las de Sila, que, claramente, son consideradas por la mayoría de las fuentes como un momento de violencia desenfrenada en el que prevaleció una ambición indecible, pero que fueron presentadas por su promotor, y deben de algún modo ser entendidas, como momentos en los que se intentó contener con seriedad el despliegue de violencia posterior a la guerra civil. La lista de las víctimas también fijó un límite cronológico, más allá del cual la inclusión en esta nómina no sería posible, y dio a la sociedad cierta claridad sobre quién estaba dentro de ese marco. Una importante sección de la tradición antigua representa las proscripciones de Sila como una instancia en la que el dictador acató el llamado al control emitido desde sectores del orden senatorial y aceptó el principio de que la violencia debía ser contenida mediante la introducción de un marco legal. La visión de que Sila había utilizado la violencia y la coerción con una medida de control no deja de tener sus parangones en la tradición y sin duda fue postulada en la obra autobiográfica de Sila. El énfasis en su habilidad para respetar los pactos fue un rasgo distintivo de una tradición en torno a su conducta y es presentado en fuerte contraste con la actitud displicente de sus enemigos. Cina no dudó en reavivar la discordia cívica poco después de la partida de Sila, 
a pesar de haber jurado públicamente no hacerlo (Plut. Sull. X.3-4); Fimbria extermina el pueblo de Ilium que lo ha dejado ingresar en su ciudad, a pesar de la clara indicación de Sila de no lastimarlos en virtud de que son sus aliados (Mithr. LIII); Sila, por el contrario, de inmediato asegura al Senado y a los itálicos su intención de respetar su posición y sus derechos (Liv. Per. LXXXVI.3). Las proscripciones del triunvirato son comparativamente menos controladas, a pesar de que el decreto de los triunviros hacía una reivindicación general de la moderación y un compromiso de concentrar la represión en los peores y más culpables; afirma una explícita preferencia por la proscripción, más que por arrestos repentinos, y una intención de limitar la violencia de los soldados (App. $B C$ IV.10). No obstante, la impresión que dan las fuentes es que la intervención de tres vencedores, en vez de uno, hace que el proceso en su totalidad sea más sanguinario y desordenado, y abre frentes de conflicto y apetitos que, de lo contrario, no habrían surgido. Amén del acto de traición política par excellance, el joven César y Cicerón, también hay lugar para la desaparición de la pietas fraternal, cuando Lépido acepta la inclusión de su hermano L. Emilio Paulo (cos. 50 a. C.) en la lista ${ }^{16}$.

\section{Pietas Y FUNDACIÓN}

En el nivel más alto del debate político e intelectual, el problema de la moderación y sus descontentos está ligado a la dificultad para fundar, o refundar, una comunidad política. Para citar un ejemplo tomado de un texto central: la muerte de Turno a manos de Eneas constituye una meditación sobre los límites de la continencia y sobre la necesidad de superarla si se debe iniciar un proceso de fundación. Se vincula tanto con la tensión entre Roma e Italia, y con el legado de la guerra civil, como con el problema de la fundación. El verbo con el que se describe el acto de infligir el golpe fatal sobre Turno es condere (ferrum sub pectore condit); esta instancia está lejos de ser aislada y marca el punto culminante de una secuencia en la cual el hundimiento de una espada en un cuerpo se transforma en un ícono de ruptura que conjura asociaciones mucho más amplias. A su vez, el empleo del verbo condere / recondere en Eneida IX-XII posee dos rasgos distintivos: siempre se aplica a la muerte de un itálico y nada se dice del destino posterior del cadáver ${ }^{17}$. La implicancia política del verbo se revela desde un nuevo ángulo: la espada puede ser enterrada en el pecho de la víctima, pero el cuerpo no recibe sepultura. Regresaremos al problema del tratamiento de los cuerpos de los vencidos y a los problemas políticos que implica.

El ritual de fundación básico, en consecuencia, se muestra bajo una luz potencialmente subversiva. La guerra civil es un contexto en el que los rituales -i.e., los rituales públicos y colectivos- son realizados con regularidad: especialmente, aunque no de manera exclusiva, porque existen ejércitos involucrados. No es necesario explicitar que las guerras civiles de fines de la República implicaban la intervención de grandes contingentes de tropas. El cumplimiento de rituales públicos de manera frecuente es central para el desarrollo de cualquier esfuerzo militar del mundo romano: los ritos de extispicio y los procedimientos augurales eran llevados a cabo con frecuencia, y el hecho de que rara vez sean reportados en las fuentes que han llegado no es evidencia de que no fueran realizados ni de que hubieran caído en algún tipo de desprecio o de descrédito. Puede asumirse con certeza que la performance de rituales religiosos podía desempeñar un papel crucial para levantar la moral o alentar a los soldados. Las consultas a los arúspices juegan un rol especialmente significativo: el valor performativo de la consulta de entrañas - un ritual que requería la participación de expertos altamente especializados, pero que podía hacerse en público- tenía un sentido claro en el contexto de una campaña militar. Se destacan dos ejemplos. Sila recibió instrucciones claras y firmes del arúspice Postumio en algunas circunstancias cruciales: antes del ataque a Nola durante la guerra social, en el año 89 a. C. (Cic., Div. I.72); en su marcha hacia Roma, en el verano del 88 a. C. (Plut. Sull. IX.7; Aug. Civ. D. II.24.1); y poco después de su retorno a Italia desde Grecia, en el 83, en Tarento (Aug. Civ. D. II.24.9-10). En estas tres ocasiones, la realización de un ritual ordinario de extispicio -algo que podría haber sucedido normalmente en varios momentos durante una campaña- reveló la emisión de sorprendentes anuncios sobre el propio dilema de Sila: que debía inmediatamente lanzar un ataque contra Nola, que debía continuar su 
marcha hacia Roma hasta la Urbs y que la victoria lo esperaba al final de la inminente guerra civil. La cualidad extraordinariamente innovadora de esas profecías está impregnada de la realización de rituales tradicionales. El poder de esas afirmaciones se basa en una reivindicación de la observancia religiosa: la pietas tradicional estaba en la base de las cualidades extraordinarias que Sila reclamaba. Cuatro décadas más tarde, durante un ritual que realizó en Spoleto, Octavio condujo un ritual de extispicio en el primer día de su potestas: nuevamente, un acto ordinario que sucede en el medio de la lucha civil para marcar el comienzo de su período en funciones ${ }^{18}$. Plinio registra un aspecto breve, aunque relativamente detallado, de la forma del hígado encontrado. El tono técnico de su resumen sugiere que descansa sobre un registro oficial de la consulta. Se considera que la forma del hígado preanuncia el inminente aumento de su poder: iba a duplicarse dentro de ese mismo año. Suetonio menciona este episodio dentro de un resumen de otras instancias en las que Octavio demostró atención a los signos divinos y en las que las respuestas recibidas produjeron patrones numéritocs valiosos: el episodio se refiere junto con la aparición de doce buitres en el cielo durante un ritual augural y poco después de una extensa discusión del horóscopo de Octavio realizado por el astrólogo Teógenes ${ }^{19}$. La piedad, en estas instancias, parece apoyar un efecto novedoso de ordenamiento del mundo, conducido a través de elecciones numerológicas específicas.

Nuevamente, un sacrificio realizado como una operación de rutina, aun durante la guerra civil, se convierte, por la predicción experta de los arúspices, en un anuncio sólido sobre la influencia perdurable del joven César en un momento de inestabilidad sin parangones. Otra vez se afirma enfáticamente el vínculo entre piedad tradicional e influencia revolucionaria, y es probable que esto haya resonado con fuerza entre los soladados. No obstante, existen repercusiones incómodas, especialmente si uno las despliega en retrospectiva. La realización de un sacrificio en Umbría a fines de los años 40 inevitablemente dirige la atención del estudioso moderno de este período a un sacrificio mucho más perturbador y controvertido, uno que ha sido objeto de gran discusión por parte de la crítica.

La captura de Perusia en el año 41 a. C. fue seguida del saqueo y la destrucción por parte de las tropas victoriosas, y del asesinato de muchos miembros ancianos del campamento de Antonio. Suetonio y Casio Dión dan un paso más, sin embargo, y relatan una versión referida por varios autores, según la cual trescientos caballeros y varios senadores fueron sacrificados en el altar en honor de Divus Iulius construido para la ocasión. Suetonio subraya que los asesinatos tuvieron lugar en los idus de marzo y del mismo modo en que se hacen los sacrificios, hostiarum more ${ }^{20}$. No se trató de un sacrificio auténtico, pero fue realizado cerca de un altar y estuvo directamente unido al legado de César. Casio Dión habla de sacrificio en términos más directos y resalta que la muerte de aquellos que no fueron indultados por Octavio (a diferencia de algunos) era algo fuera de lo común ${ }^{21}$. De manera más interesante para nuestros objetivos, enmarca este suceso perturbador en un patrón de piedad que es al mismo tiempo reafirmado y amenazado. La masacre se acompaña de la destrucción de la ciudad, que sólo perdona el templo de Vulcano y una estatua de Juno. Esta última eventualmente es quitada de allí y llevada a Roma: Casio Dión afirma que esto se hizo de acuerdo con un sueño que el joven Caesar había tenido. Obtener a partir de esta tradición un relato histórico coherente de cómo se desarrollaron en realidad las repercusiones de Perusia es probablemente una ambición inapropiada. Existen, sin embargo, dos temas que sobresalen: por un lado, la afirmación del vínculo entre el castigo de los vencidos y el tributo al legado de Julio César - pietas para con él, con un modo discursivo sacrificial que prevalece sobre cualquier referencia al proceso que llevó a las ejecuciones $-{ }^{22}$. Por otro lado, la destrucción de Perusia es considerable, pero no total. Se rescatan dos objetos sagrados, y uno de ellos es apropiado por Octavio, tanto de manera física (por su traslado a Roma) como ideológica (por su aparición en un sueño del joven César). Este último detalle destaca con firmeza la piedad del triunviro en esa situación altamente controvertida: sea cual fuere la firme acción que emprendió, la realizó con un fuerte foco en las consideraciones dictadas por la pietas para con los dioses y su padre fallecido. 


\section{Pietas local}

Por supuesto, un relato de esa clase no era aceptado unánimemente. La postura de otra comunidad umbria en esa misma fase de la guerra civil dirige la atención hacia otro aspecto de la piedad y su importancia en este contexto: el tratamiento de los muertos. El papel de la "mala muerte", la male mort, en la fase de las proscripciones, ha recibido considerable interés; el tratamiento de los cuerpos de los muertos en batalla, comparativamente, ha sido objeto de mucha menos atención ${ }^{23}$. La tradición acerca de las arae Perusinae presenta ambos problemas en los dos sentidos: desde una posible lectura, las víctimas son tratadas como animales, efectivamente deshumanizadas; lejos de ser un acto de piedad, su matanza puede verse como una denuncia de la conducta de Octavio ${ }^{24}$. En una guerra civil, tal como nos recuerda el pasaje de Tácito con el que comenzó la discusión, no era raro que los cuerpos de los vencidos quedaran sin sepultura, especialmente cuando la derrota era total. No obstante, no existe una norma estricta. En las fases tempranas de la guerra perusina, la ciudad de Nursia era parte de la coalición que tomó las armas contra Octaviano; luego, llegó a un acuerdo con el triunviro antes de ser atacada en forma directa ${ }^{25}$. El pueblo preparó entonces un enterramiento comunal para los ciudadanos que habían muerto en las operaciones militares contra César, y la inscripción en el monumento hacía referencia explícita a su lucha en nombre de la libertad. Su participación en una guerra civil no fue eliminada; lejos de ello, era afirmada con orgullo como ejemplo de su patriotismo y su compromiso civil. Nursia puede haber sido una comunidad autogobernada, pero de ciudadanos romanos, y su enfático compromiso con Libertas era una intencionada referencia al principio que separa a los ciudadanos de los súbditos y los esclavos ${ }^{26}$. En su nombre se pagaban las deudas de los muertos y su sacrificio colectivo era celebrado a través de un marco comunitario. Octaviano no aceptó esa elección con agrado y castigó a la ciudad con una multa de consecuencias duraderas. Ni Suetonio ni Casio Dión sugieren que hubiera algo anómalo en la decisión de los nursinos de construir un memorial en honor de sus muertos y de colocarle una inscripción ${ }^{27}$. La controversia giraba en torno de la afirmación política que la inscripción realizaba.

La decisión de construir monumentos en el contexto de una guerra civil no era excepcional en este período, como tampoco eran aisladas las preocupaciones políticas que respaldaban la decisión del pueblo de Nursia. De hecho, encuentran un poderoso eco en el núcleo mismo del discurso político romano, nuevamente en la Filípica XIV. En el mismo discurso en el que articulaba el argumento a favor de considerar a Antonio como un enemigo externo y de saludar los logros de aquellos que lo habían derrotado con la misma acción ritual que se reservaba a los vencedores de enemigos extranjeros, Cicerón presenta una cuestión relacionada. Los méritos de los comandantes que han ganado en Mutina merecen ser agradecidos, pero los logros de los soldados que han perdido sus vidas en la batalla también deben recibir un reconocimiento muy solemne. En consecuencia, propone construir un monumento de magnitud adecuada en honor de los soldados de la legio Martia que murieron en Mutina (31: monumentum fieri quam amplissimum) ${ }^{28}$. La elección de esta legión está explícitamente determinada por la cantidad de pérdidas que ha sufrido. La Quarta, que estuvo involucrada en el mismo frente, no sufrió ninguna y, por lo tanto, tiene menor necesidad de que se reconozcan sus méritos y el alcance de la pérdida y el pesar con el que debió enfrentarse. La conexión obvia de la legión con Marte permite a Cicerón extenderse bastante sobre sus extraordinarias hazañas: una operación que se torna más necesaria ya que, como él mismo admite, la decisión de conceder un monumento en honor de una legión perdida nunca ha sido tomada en el pasado, después de ninguna de las guerras libradas por Roma. Lo que garantiza el pedido es la dimensión de la amenaza que Roma ha enfrentado a manos de Antonio: una clase excepcionalmente insidiosa de enemigo externo. La victoria contra un rival que había sido miembro del cuerpo político claramente justifica un tipo de honor extraordinario y sin precedentes. Tenemos que confiar en la palabra de Cicerón en este sentido, pero no hay razón aparente por la cual haya tenido que exagerar su argumento en esta ocasión. No hay aquí menciones a la guerra civil, por supuesto: Cicerón ha dedicado una significativa parte de su argumentación a negar que se esté desarrollando realmente una guerra civil. Sin 
embargo, la naturaleza excepcional de las circunstancias nunca es explicitada por completo y, por el contrario, se coloca un fuerte énfasis en la necesidad de dar consuelo a las familias (34) y en subrayar, ante ellas y ante la comunidad como un todo, que la acción emprendida por esa legión fue decisiva para evitar el desastre. En este punto, Cicerón encuadra el problema en términos de piedad tradicional, desdibujando eficazmente las esferas privada y pública: se recordará a las familias de los muertos su valor (virtutem), la piedad (pietatem) del pueblo, la lealtad (fidem) del senado y, de modo más general, la memoria de un conflicto muy cruel. El énfasis en la necesidad de dar consuelo a los familiares se presenta en franco contraste con la definición del accionar de Antonio como un parricidium, y coloca en foco de manera más pronunciada el horizonte conceptual de pietas: Antonio trata a su patria como los parricidas tratan a sus padres, y exhibe la misma impactante falta de pietas que el pueblo romano es llamado a demostrar. La guerra está eficientemente presentada como un choque entre pii e impii (32).

El monumento imaginado por Cicerón estaba pensado, sin duda, como un cenotafio: es lógico dar por sentado que quienes habían caído en Mutina estaban enterrados en las cercanías del campo de batalla, probablemente en fosas comunes, como sabemos que sucedió en Farsalia ${ }^{29}$. Sin embargo, había algunas excepciones. Los dos cónsules del 43, A. Hirtio and C. Vibio Pansa, que perdieron la vida en Mutina, fueron enterrados en el Campo Marcio, probablemente en el borde de una finca propiedad de Marco Antonio ${ }^{30}$. Había precedentes para ello: una breve referencia en Apio menciona la llegada a Roma de los cuerpos del

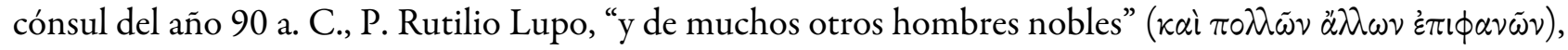
y el impacto emocional devastador que ejerció ${ }^{31}$. La función del monumento propuesto por Cicerón en la primavera del 43 era rendir homenaje a aquellos que habían perdido sus vidas en Mutina y enmarcar su presencia dentro del paisaje de la Urbs. Se trataba de exhibir una resolución al conflicto civil a través de la afirmación de su legado en el centro mismo de Roma. El objetivo era celebrar ese momento haciéndolo excepcional: reconociéndolo como un hito de mayor significación y dificultad, lo cual requiere una acción extraordinaria. Se trataba de generar una apariencia de orden después del trauma de Mutina: un orden que llegará a partir de la inauguración de un monumento público que, como Cicerón subraya, no será solamente un artefacto visual, sino que estará acompañado y confirmado por una inscripción que dará eterno testimonio a su "divino valor" (33: litterae diuinae uirtutis testes sempiternae).

El vínculo entre pietas y memoria posee enorme significación política. Reconocer los procesos políticos por lo que implican y asegurar su correcta interpretación en el futuro es de importancia fundamental, y los monumentos juegan un papel crucial en posibilitarla. De aquí la necesidad de argumentar a favor de monumentos que pueden transmitir mensajes políticos divisorios: el cenotafio de Mutina no es una excepción en esta encrucijada histórica. Cuando su amigo, el consular Ser. Sulpicio Rufo, murió por causas naturales durante una embajada que lo llevaba a la Galia Cisalpina para dialogar con Antonio, en enero del 43 a. C., Cicerón dedicó una parte significativa de la Filípica IX a la necesidad de dedicarle una estatua, como era habitual en el caso de aquellos que habían recibido muerte violenta durante asuntos diplomáticos (10). Esa estatua no sería simplemente un monumento: debía estar acompañada de un enterramiento público (14: sepulcrum publice decernendum $)^{32}$. Nuevamente, pietas juega un papel significativo, sin duda destacado: la pietas del hijo de Sulpicio (12) es individualizada como un factor principal para movilizar el interés y la simpatía por la desgracia de su padre y es, al mismo tiempo, un modelo de esa misma virtud exhibida por el padre $(9,12)$.

Los eventos de Perusia y Nursia es un poderoso ejemplo de la importancia de la dimensión local en las dinámicas de la piedad en la edad de las guerras civiles tardorrepublicanas. Esto no sorprende en absoluto en un contexto en el que gran parte del impacto de las guerras se experimenta y se negocia en el nivel de la comunidad individual, en un mundo en el que el horizonte de la mayoría de la gente sigue siendo el de la propia comunidad, y donde cada comunidad política mantiene sus estructuras religiosas y sus marcos regulatorios, sus sacra ${ }^{33}$. Las duae patriae de las que habla Cicerón en términos tan famosos y elevados ( Leg. 
II.3-5) son, en gran medida, un producto de élite, un interés de una minoría ${ }^{34}$. Gran parte del marco analítico de esta discusión ha sido provista por Cicerón, notablemente por su obra de los últimos años: no es necesario recordar cuán parcial e imperfecto es este invaluable punto de vista a los fines de la reconstrucción histórica. $\mathrm{Al}$ señalar los límites de nuestra fuente principal para este período, no es, quizás, inoportuno lamentar las consecuencias de la pérdida de una fuente valiosa. Está fuera de duda que nuestra comprensión del papel de las ciudades en los mecanismos de la piedad en la era de las guerras civiles tendría un basamento mucho más sólido si hubieran sobrevivido los libros relevantes de $A b$ urbe condita de Livio. Podríamos, por ejemplo, indagar con mucho más detalle el valor y el significado de su afirmación de que la neglegentia en asuntos religiosos ha triunfado en su época y de que los prodigios ya no se reportan (XLIII.13); también podríamos interpretar mejor el contexto religioso y ritual en el que deben entenderse los prodigios (o portentos, como sin duda es más prudente llamarlos) listados en este período por Casio Dión y, en menor medida, por Suetonio. El despliegue de omina reportados en las vísperas de los idus de marzo, por ejemplo, sugiere con fuerza que todavía existía la infraestructura que por largo tiempo había posibilitado la transmisión de relatos de prodigios desde las comunidades locales a Roma. Lo que nos falta para este período es una fuente narrativa que registre de manera sistemática los procesos de expiación llevados a cabo luego del reporte de prodigios: algo que Livio hace sistemáticamente, y en lo que ni Apio ni Casio Dión están interesados. El conjunto de avisos de prodigios que Obsequente registra para los años 43 y 42 a. C. muestra más allá de toda duda que Livio retuvo un entusiasta foco narrativo en el papel de las advertencias divinas y la calidad de las respuestas diseñadas ${ }^{35}$. Ciertamente, la mayoría de los sucesos registrados en esos años se vinculan con contextos militares: existe, no obstante, un episodio notable documentado para el año 47 a. C. que afecta a Patavio, lugar de nacimiento del historiador. Se dice que el augur C. Cornelio había realizado su acostumbrado ritual de ornitomancia y que había visto signos que anunciaban la victoria de César. El episodio es conocido por nosotros, sin duda alguna, porque involucra una ciudad que Livio conocía bien; incluso es posible que lo haya presenciado él mismo ${ }^{36}$. No hay motivos, sin embargo, para considerar en modo alguno a Patavio como una excepción, tanto en la realización ininterrumpida de sus sacra locales, como en el intento de usarlos como herramienta para involucrarse en los eventos del contexto más amplio.

En un polo diferente del espectro político, y en un contexto geográfico muy distinto, la necesidad de sostener la piedad en los escenarios locales es evidente a partir de una inscripción que C. Calvisio Sabino montó en Spoleto (muy probablemente su lugar de nacimiento), en la que Pietas está en la primera línea, y se realiza una reivindicación sobre ella luego de la guerra de Perusia. Una inscripción de Spoleto celebra la pietas de C. Calvisio Sabino, uno de los dos senadores que habían buscado defender a César en los idus de marzo: Pietati / C(ai) Calvisi C(ai)f(ili) Sabini, / patroni, co(n)s(ulis), / VIIvir epul(onum), cur(ionis) $\max (\text { imi })^{37}$. Esta inscripción data de un momento bastante avanzado de la carrera de Calvisio, luego de su ascenso al consulado, en el 39 a. C. En la lectura de Syme, es un poderoso documento de algunas de las principales tendencias históricas de su época. Es un testimonio de la perdurable conexión entre un hombre de origen municipal que ha llegado a un cargo público de alto rango en Roma y su pueblo natal: su papel de patrono de Spoleto está intencionalmente anunciado junto con (y, de hecho, inmediatamente antes de) su consulado $^{38}$. La decisión de colocar a Pietas en la primera línea, de todos modos, es incluso más instructiva: el tema se había vuelto especialmente significativo después de la ruptura de las relaciones entre Octavio y Q. Salvidieno Rufo, que había sido designado para el consulado del año 39 a. C. Es posible que Calvisio fuera, como dijo Syme, el "ganador" en el fin de Salvidieno ${ }^{39}$. Subrayar y celebrar su pietas, una cualidad aplicada a sus amistades políticas, era al mismo tiempo un modo de homenajear una virtud que había posibilitado su ascenso político y una oportunidad de responder al discurso que Octaviano había estado configurando desde su regreso de Epiro. También establecía una poderosa conexión entre guerra y paz: del mismo modo que pietas había sido central en el esfuerzo de la guerra contra los asesino de César, era ahora una cualidad central para reivindicar cuando el gobierno civil se estaba restableciendo, en Roma y en toda Italia. Calvisio podía 
incluso respaldarlo refiriéndose a su capacidad como sacerdote. Era miembro de un colegio distinguido, el de los septemviri epulonum, y único poseedor de un sacerdocio antiguo que se vinculaba con las curiae y sus asambleas de votación: una figura clave en el mantenimiento de las negociaciones ordenadas y efectivas entre el pueblo como comunidad política y los dioses ${ }^{40}$.

El astro político de Calvisio pronto decayó cuando su contribución a la campaña contra Sexto Pompeyo resultó menos que exitosa ${ }^{41}$. El peso de la referencia a su propia pietas, no obstante, tiene una significación que excede su propia trayectoria personal y nos lleva al corazón de las complejidades de lo que puede entenderse como una cultura de la guerra civil en la primera mitad del siglo I a. C. En un momento de disrupción completa, mortal, mientras la cohesión cívica se desintegra, las reivindicaciones en torno a la piedad se transforman en una estrategia para afirmar líneas de continuidad con el pasado. Si una cultura de la guerra civil realmente tomó forma en la Roma tardorrepublicana, la negación debe haber sido una parte central.

$* * *$

Lo que se ha propuesto aquí es meramente un panorama variado y selectivo de las funciones y modos de discurso que la piedad puede cumplir en el período tardorrepublicano. Su propósito central ha sido expresar una idea del vaste programme que implica el estudio de la piedad en la era de la guerra civil. El debate sobre las obligaciones que uno tiene para con la familia, los conciudadanos y los dioses impacta en todos los aspectos cruciales de la vida política de la época. Ya sea que la discusión gire en torno a cómo definir los límites de la comunidad política, proponiendo un llamado a la moderación, o defendiendo la represión a gran escala o afirmando un nivel de continuidad con el pasado en un momento de cambio traumático, las consideraciones sobre la piedad se revelan centrales. Mientras se desarrolla una guerra civil, la necesidad de piedad se hace más urgente que nunca antes. Si existe una cultura de la guerra civil, pietas debe ser uno de sus rasgos definitorios. A la luz de ese trasfondo, entonces, el resurgimiento augusteo, la invención y la reinvención de instituciones religiosas deben ser tomados con mayor seriedad todavía. La piedad no fue robada ni tampoco estaba disponible para quien la quisiera: como convenía a una época espantosa, era una regla clave de compromiso para todos los sectores enfrentados.

\section{Notas}

1 Aug. RG XXXIV.2

2 Roller, M. B. (2001) Constructing Autocracy. Aristocrats and Emperors in Julio-Claudian Rome, Princeton and Oxford, 27. Cf. Syme, R. (1939) The Roman Revolution, Oxford, 448: "Virtus and pietas could not be dissociated".

3 Powell, A. (2008) Virgil the Partisan. A Study in the Re-integration of Classics, Swansea.

4 Powell, A., Virgil the Partisan, 31-85, esp. 77.

5 Welch, K. (2012) Magnus Pius. Sextus Pompeius and the Transformation of the Roman Republic, Swansea, esp. 291-318.

6 Syme, R., The Roman Revolution, 157.

7 Un empleo tan abiertamente politico de pietas no equivale a su irrelevancia desde el punto de vista cultural: cf. el comentario sobre Prop. III.22.21-22 en p. 448 ("Though debased by politics, the notion of pietas had not been entirely perverted").

8 Ulrich 1930 (Pietas-pius alspolitischer Begriff im römischen Staat bis zum Tode des Kaisers Commodus, Breslau) continúa siendo una valiosa lectura acerca de pietas.

9 Acerca del saqueo de Cremona y sus consecuencias, ver Santangelo, F. (2017) 'Vespasiano: il rapporto con la città', en L. Passi Pitcher et al. (eds.), Amoenissimis... aedificiis. Gli scavi di Piazza Marconi a Cremona. Volume I: lo scavo, Mantua, 83-86.

10 Chilver, G. E. F. (1979) A Historical Commentary on Tacitus' Histories I and II, Oxford, 231.

11 Lange, C. H. (2016) Triumphs in the Age of Civil War. The Late Republic and the Adaptability of Triumphal Tradition, Londres, especialmente 49-124.

12 Cf. Lange 2016, Triumphs in the Age of Civil War, 84-85. Sobre las supplicationes de César, ver Weinstock, S. (1971) Divus Julius, Oxford, 63-64; Roller 2001, Constructing Autocracy, 57-58.

13 Lange 2016, Triumphs in the Age of Civil War, 86-90; ver también Havener, W. (2015), "Triumphus ex bello civili? Die Präsentation des Bürgerkriegssieges im spätrepublikanischen Triumphritual”, en H. Börm, M. Mattheis y J. Wienand (eds.), Civil War in Ancient Greece and Rome. Contexts of Disintegration and Reintegration, Stuttgart, 166-167 y 2015, 
168-173, con un énfasis diferente en la noción de hostis y los problemas que presentaban los triunfos sobre los ciudadanos romanos. Para un breve panorama de los sucesos posteriores a Mutina, ver Allély, A. (2008) La Déclaration d'hostis sous la République romaine, Bordeaux, 98-100, 248-249.

14 Acerca de este episodio, ver Nicholls, J. J. (1967) "The Content of the lex curiata", AJPh 88, 269-270 y Van Haeperen, F. (2012) “Auspices d'investiture, loi curiate et légitimité des magistrats romains”, $C C G G 23,104-107$, quienes consideran que los argumentos invocados por los pompeyanos como un pretexto débilmente ocultado.

15 Tac. Ann. III.51.2 = FRHist 26 F 132. Véase Ash, R. (2010) “Tarda Moles Ciuilis Belli: The Weight of the Past in Tacitus' Histories”, en B. W. Breed-C. Damon-A. Rossi (eds.), Citizens of Discord: Rome and its Civil Wars, Oxford, 126-128.

16 App. $B C$ IV.12; cf. Casio Dión XLVII.8.1, quien informa que apoyó la huida de su hermano.

17 Véase James, S. (1995) “Establishing Rome with the Sword: condere in the Aeneid", AJPh 116, 623-637; Rimell, V. (2015) The Closure of Space in Roman Poetics. Empire's Inward Turn, Cambridge, 53-54.

18 Plin. Nat. XI.190; Suet. Aug. 95.2.

19 Suet. Aug. XCIV.12-95. Para una discusión completa, ver Wardle, D. (2014) Suetonius. Life of Augustus, Oxford, 530-535.

20 Suet. Aug. XV.1.

21 Cass. Dio XLVIII.14.4.

22 Syme 1939, The Roman Revolution, 212 imagina asesinatos judiciales, para lo cual no hay evidencia.

23 Cf. Hinard, F. (1984) 'La male mort. Exécutions et statut du corps au moment de la première proscription', en $D u$ châtiment dans la cité. Supplices corporels et peine de mort dans le monde antique, Roma, 295-311.

24 Sen. Ben. I.15.1 habla de las arae Perusinae. App. BCV.48-49 tiene una versión ampliamente diferente: Octavio perdonó en forma pública a sus enemigos romanos y a la ciudad de Perusia, y ejecutó sólo a los miembros del senado local; tenía pensado dejar que sus soldados saquearan la ciudad, pero el fuego que llevó a la destrucción fue causado por un ciudadano que había decidido quemar su propia casa; cf. Vell. II.74.4. Sobre este aspecto de la tradición de la guerra de Perusia, ver Gabba, E. (1970) Appiani Bellorum Civilium Liber Quintus, Florence, 80-82; Gowing, A. M. (1992) The Triumviral Narratives of Appian and Cassius Dio, Ann Arbor, 84; Westall, R. (2017) "The Sources of Cassius Dio for the Roman Civil Wars of 49-30 BC”, en C. H. Lange y J. M. Madsen (eds.), Cassius Dio. Greek Intellectual and Roman Politician, Leiden y Boston, 57-62.

25 Suet. Aug. XII.1 (donde se afirma que el monumento honraba a los ciudadanos de Nursia que habían muerto en la guerra de Mutina); Cass. Dio. 48.13.6. Wardle 2014, Suetonius. Life of Augustus, 129 señala que el relato de Casio Dión es preferible al de Suetonio debido a su "greater detail and logic". Westall 2017, "The Sources of Cassius Dio", 62 subraya la relación entre este episodio y la guerra de Perusia en Casio Dión.

26 Una inscripción fragmentaria $(A E 1996,534)$ sugiere que Nursia pudo haber recibido poco antes un contingente de colonos simpatizantes de Antonio inmediatamente después de Filipos (Panciera, S. (2006a), "Storia locale dell'Italia romana. Nursia colonia antoniana”, en M. Silvestrini et al. (eds.), Scritti in onore di Francesco Grelle, Bari = Panciera, S. (2006b) Epigrafi, epigrafia, epigrafisti. Scritti vari editi e inediti (1956-2005) con note complementari e indici, 3 vols, Rome, 965-976; Gallo, A. (2018) Prefetti del pretore e prefetture. L'organizzazione dell'agro romano in Italia(IV-I sec. a.C.), Bari, 171-172). Si Nursia era una Colonia Concordia Antonia Ultrix, como sugiere Panciera, el castigo de la comunidad por Octaviano pudo haber ascendido a revocar su estatus colonial y ordenar a los colonos o bien comprar la tierra que se les había adjudicado o bien partir (ver Panciera 2006a, "Storia locale dell'Italia romana”, $188=$ Panciera 2006b, Epigrafi, epigrafia, epigrafisti, 973).

27 Cooley, A. (2012), "Commemorating the War Dead of the Roman World", en P. J. Rhodes (ed.), Cultures of Commemoration. War Memorials, Ancient and Modern, Oxford, 76 ve la decisión del pueblo de Nursia como excepcional.

28 Véase Cooley 2012, "Commemorating the War Dead of the Roman World”, 64-66.

29 Cf. App. $B C$ II.82, donde también se menciona la decisión de César de otorgar un enterramiento especial a su valiente centurión Crasinio. Plin. Nat. 7.187 afirma que la cremación se utilizaba en la Roma republicana, especialmente a partir del comienzo de las guerras transmarinas.

30 Véase Coarelli, F. (1999), "Sepulcrum: A. Hirtius”, en E. M. Steinby (ed.), Lexicon Topographicum Urbis Romae 4, Roma, 290-291 y Macciocca, M. (1999) “Sepulcrum: C. Vibius Pansa”, ibidem, 302 para una discusión detallada de la evidencia arqueológica. Gerding, H. (2008), "Reconsidering the Tomb of Aulus Hirtius”, OpAthRom 1, especialmente 151, defiende la restauración o reconstrucción augustea de las tumbas.

31 App. $B C$ I.43.

32 Véase Cooley 2012, “Commemorating the War Dead of the Roman World”, 65-66.

33 Raggi, A. (2011) "Religion in Municipal Laws?", en J H. Richardson y F. Santangelo (eds.), Priests and State in the Roman World, Stuttgart, 333-343.

34 Sobre este tema, cf. las perspicaces observaciones de Carlà-Ühink, F. (2017a) "Alteram loci patriam, alteram iuris: 'Double Fatherlands' and the Role of Italy in Cicero's Political Discourse”, en L. Cecchet y A. Busetto (eds.), Citizens 
in the Graeco-Roman World. Aspects of Citizenship from the Archaic Period to AD 212, Leiden-Boston, 259-262 y CarlàÜhink, F. (2017b) The "Birth" of Italy: The Institutionalization of Italy as a Region, 3rd-1st Century BCE, Berlín y Nueva York, 282-283.

35 Obs. 65a; cf. Plut. Caes. XLVII.3-6; Cass. Dio XLI.16.4-5.

36 La formulación de Plut. Caes. XLVII.6 lo sugiere con fuerza. Cf. Westall 2017, “The Sources of Cassius Dio”, 55-57 sobre los relatos de este episodio que han sobrevivido.

37 CIL 11.4772; véase Syme, R. (2016) "Rome and Umbria”, en Approaching the Roman Revolution. Papers on Republican History, ed. F. Santangelo, Oxford, 314-335, con los addenda bibliográficos en 381-382; Andermahr, A. M. (1998) Totus in praediis: senatorischer Grundbesitz in Italien in der frühen und hohen Kaiserzeit, Bonn, 203-204; Kavanagh, B. (2009) "Senators and Senatorial Politics in Julio-Claudian Spoletium", Epigraphica 71, 88-89

38 La conexión con Spoleto por cierto no descarta la vinculación con otros contextos regionales: una inscripción de Canusio lo menciona a la vez como cónsul y como patrón de la comunidad (CIL 9.414 = Epigrafi romane di Canosa I, no. 20); la presencia de L. Calvisii de estatus liberto sugiere que también tenía intereses económicos a largo plazo en la región. Cf. Grelle, F. et al. (2017) La Puglia nel mondo romano. Storia di una periferia. L'avvio dell'organizzazione municipale, Bari, 134-135; véase 55, 63 sobre su acción militar en Apulia en el 36 a. C.

39 Syme 2016, "Rome and Umbria", 331.

40 Acerca del curio maximus, ver Smith, C. J. (2006) The Roman Clan. The gens from Ancient Ideology to Modern Anthropology, Cambridge, 216. Cf. n. 14 sobre el papel de la lex curiata para la estrategia de los pompeyanos en el 48.

41 Syme 2016, "Rome and Umbria", 334-335.

\section{INFORMACIÓN ADICIONAL}

Traducción: María Emilia Cairo emiliacairo@conicet.gov.ar 